\title{
Deviance in Fetal Growth and Risk of Autism Spectrum Disorder
}

Kathryn M. Abel, M.D., Ph.D.

Christina Dalman, M.D., Ph.D.

Anna C. Svensson, M.Sc., Ph.D.

Ezra Susser, M.D., Dr.P.H.

Henrik Dal, M.Sc.

Selma Idring, M.D.

Roger T. Webb, M.Sc., Ph.D.

Dheeraj Rai, M.B.B.S., M.R.C.Psych.

Cecilia Magnusson, M.D., Ph.D.

\begin{abstract}
Objective: Understanding the relationship between fetal growth and autism spectrum disorder (ASD) is likely to advance the search for genetic and nongenetic causes of ASD. The authors explored the associations between fetal growth, gestational age, and ASD with and without comorbid intellectual disability in a Scandinavian study population.
\end{abstract}

Method: The authors conducted a matched nested case-control study within the Stockholm Youth Cohort that included all children ages 0-17 who resided in Stockholm County from 2001 to 2007 $(\mathrm{N}=589,114)$. The authors identified 4,283 children with ASD: 1,755 with intellectual disability and 2,528 without, and they selected 36,588 age- and sex-matched comparison subjects. ASD case subjects were ascertained from unique identifiers assigned to all Swedish residents and linkage with official registers covering all pathways of assessment or care of ASD in Stockholm County. The authors calculated $z$ scores of deviance in fetal growth from a reference curve using records from the national Swedish Medical Birth Registry, which included ultrasound dating of gestational age as well as birth weight. Crude and adjusted odds ratios for ASD, ASD with intellectual disability, and ASD without intellectual disability were the main outcome measures.

Results: ASD risk increased with fetal growth 1.50 standard deviations below and $>2.00$ standard deviations above the mean for gestational age; the greatest risk was for fetal growth that was less than 2.00 standard deviations below the mean (adjusted odds ratio $=1.70 ; 95 \% \mathrm{Cl}=1.44-2.01)$ or greater than 2.00 standard deviations above the mean (adjusted odds ratio=1.50; $95 \% \mathrm{Cl}=1.27-1.77)$. The same overall pattern was observed for ASD with and without intellectual disabilities. However, poor fetal growth (i.e., growth below the mean) was more strongly associated with ASD with intellectual disabilities than without. Regardless of fetal growth, preterm birth increased ASD risk.

Conclusions: Deviance in fetal growth at either distributional extreme may be a significant antecedent to the development of ASD through genetic and/or nongenetic mechanisms.

(Am J Psychiatry 2013; 170:391-398)

\begin{abstract}
A utism spectrum disorder (ASD) comprises a group of developmental disorders characterized by impairments in social interaction and communication and stereotyped interests and behaviors (1). Consistent increments in the observed prevalence of ASD are acknowledged as a pressing public health concern, with up to $2 \%$ of children developing ASD (1). The importance of genetic causes has long been recognized, and substantial advances have been made in identifying genetic contributions, including rare de novo variants strongly related to ASD and common polymorphisms that provide weaker contributions to risk (2). However, recent studies (e.g., 3) have highlighted the potential for nongenetic or shared environmental factors to play a significant role in the causes of ASD.

The processes that lead to ASD probably begin during fetal development, as signs can appear early in life. Poor fetal growth has been associated with a variety of cognitive and psychiatric problems in children (4) that overlap with difficulties experienced in ASD and a range of adult mental
\end{abstract}

disorders (5). For example, poor fetal growth is related to speech and language deficits, internalizing and attention problems, social difficulties (6), hyperactivity (7), and learning disabilities (8). In most studies with accurate recording of birth weight and IQ, birth weight up to $4,000 \mathrm{~g}$ has been associated with IQ even in same-sex sibling pairs (9). Almost all studies of ASD report a substantial proportion of comorbid intellectual disability, although this varies across studies from approximately $15 \%$ to $60 \%(1,10)$.

Fetal growth is influenced by genetic and nongenetic factors (4). A detailed understanding of how fetal growth and ASD are associated is likely to advance the search for causes of ASD with and without intellectual disability; however, key methodological problems challenge the existing evidence. First, many studies of the association between ASD and fetal growth have assessed birth weight, which is a rather crude measure of fetal growth. Second, other studies derive sex-specific birth weight for gestational age from live births, which yields a biased measure 
of birth weight for gestational age for preterm births because of selective survival $(11,12)$. In Sweden, early ultrasound dating provides an intrauterine weight-based standard that is superior to the conventional birth weight for gestational age in yielding an unbiased measure and predicting perinatal morbidity and mortality (13). Third, in studies of both birth weight and birth weight for gestational age, most have dichotomized exposure into normal versus low birth weight (14-17), or appropriate for gestational age versus small for gestational age $(16,18,19)$, rather than examining associations between ASD and a continuous measure of fetal growth (i.e., the degree of deviance in growth above and below the norm in the general population from which case subjects derive). Fourth, study samples have been too small to provide enough case subjects in the extreme exposure categories $(<2.5 \mathrm{~kg}$ or $>4.5 \mathrm{~kg}$ ) (e.g., 14, 20). Fifth, studies rarely distinguish between ASD with and without intellectual disability in calculating risk. Since fetal growth is related to intellectual disability, the relationship between fetal growth and ASD may differ in individuals with and without intellectual disability. Finally, many studies have used selected subsets of children with ASD, such as children in psychiatric inpatient care $(16,17)$. Thus, previous findings may not pertain to the broader population of children now identified on the autism spectrum.

We addressed these limitations by using the Stockholm Youth Cohort, a prospectively studied total population sample in which data from children with ASD were systematically ascertained $(21,22)$. We examined fetal growth as a continuum in a sample of sufficient size to disentangle the relationships between fetal growth, gestational age, and ASD; to evaluate continua extremes; and to differentiate between effects with and without intellectual disability. We hypothesized that deviance from the mean in growth (either below or above) would be associated with greater risk of ASD.

\section{Method}

\section{Design and Study Population}

The research ethics committee at Karolinska Institute granted approval for the study. We conducted a matched nested casecontrol study within the Stockholm Youth Cohort (22), which includes all children ages 0-17 who resided in Stockholm County between 2001 and 2007 (N=589,114). The Stockholm Youth Cohort population was identified using the Swedish Registry of the Total Population (http://www.socialstyrelsen.se/statistics; 23), and prospective data from probands and their first-degree relatives were collected using records linked with Swedish national and regional health and administrative registries (22). Exclusion criteria and characteristics of the sample included in our study are listed in Figure 1 of the data supplement that accompanies the online edition of this article. First, we excluded those who had not resided in Sweden or Stockholm County for at least 4 years $(\mathrm{N}=144,187)$. This enabled us to exclude children too young to have a diagnosis and ensured that migrant children with ASD had enough time to undergo assessment and diagnosis. From the remaining children, we excluded all adoptees ( $N=5,636)$. This resulted in 439,291 children and adolescents. We then excluded children who were not born in Sweden, whose obstetric information was not available (mainly those who were born abroad), and twins. These criteria excluded approximately $10 \%$ of the remaining individuals. Data on other relevant covariates were missing from $4 \%$, leaving 4,283 children with ASD (1,755 with intellectual disability and 2,528 without) and 36,588 age- and sex-matched healthy comparison subjects who were randomly selected from the control population in the Stockholm Youth Cohort. Ten comparison subjects were originally matched per ASD child, but following the exclusions described above, a median of nine matched comparison subjects remained for each case subject.

\section{Case Ascertainment}

Data from children with ASD were ascertained using the unique identity numbers assigned to all Swedish residents and an exhaustive multisource linkage with registries covering all pathways of assessment or care of ASD in Stockholm County (21-24). In the Stockholm Youth Cohort, infants and preschool children are offered a structured assessment of social, motor, language, and cognitive development at centers whose health and surveillance program engages $99.8 \%$ of all preschool children (22). Assessments are performed by trained nurses at regular intervals $(1,2,6,10-12,18,36,48$, and 60 months), at regular pediatrician examinations ( 2,6 , and 10-12 months), and at other intervals according to need or in case of developmental deviation (22). Referrals for assessment of suspected ASD are commonly made by child health care centers and can also be requested by parents through family practitioners, schools, and other health or social care agencies.

Most autism-related services in Stockholm County (diagnosis, follow-up health, special education, and social care) use regional guidelines to assess developmental disorders like ASD and intellectual disability (24). The guidelines recommend agestandardized neuropsychiatric cognitive testing and structured assessments of social, medical, and developmental history by parental report and by observation of the child in natural settings by specialist teams (22). Structured follow-up is provided according to the presence or absence of comorbid intellectual disability (defined as IQ of 70 or less). Intellectual disability in the Stockholm Youth Cohort was ascertained as a comorbid diagnosis of ICD-9 codes 317-319 or ICD-10 codes F70-F79 and DSM-IV codes 317-319 and supplemented using the Habilitation Register, which categorizes service recipients as having ASD with or without intellectual disability. These categories were recently validated by a child psychiatrist and a neuropediatrician who investigated record-based evidence related to the diagnosis of ASD or intellectual disability according to ICD-10 and DSM-IV classification (22).

Unlike in most population studies, our case subjects included those requiring health services and special education or social care. This is important because most children with ASD may not access health services after diagnosis, but receive input from social and educational agencies. Thus, we were likely to capture most children with an ASD diagnosis in Stockholm County with high validity $(21,22)$. The 2007 prevalence of ASD in the Stockholm Youth Cohort was 114.8 per 10,000 (95\% confidence interval $[\mathrm{CI}]=111.7-118.0$ ) (22), which is almost identical to other population prevalences. We were able to differentiate between ASD with and without intellectual disability, following the service delivery models in Sweden, which is an informative subclassification strategy (25). We were unable to study ASD according to the subclasses used in current classification systems because this information was not consistently available in the registers. 


\section{Exposure Variables}

Prospectively recorded information on birth weight and gestational age was retrieved from the Swedish Medical Birth Register (26). Since 1990, approximately $95 \%$ of Swedish women have received ultrasound screening in the second trimester; ultrasound measurements of fetal size determine the gestational age of the fetus and thus gestational age at birth and birth weight for gestational age. The pregnancies without ultrasound data were dated from the first day of last menstruation. We calculated $\mathrm{z}$ scores of deviance in fetal growth from the reference curve for estimated fetal weight, because an intrauterine weight-based standard is superior to the conventional birth weight for gestational age standard in predicting perinatal morbidity and mortality (12). These $\mathrm{z}$ score groups were stratified according to conventions of standard deviations as narrowly as the data would allow at the extremes of distributions. Gestational age was stratified to represent recognized clinical categories of preand postterm birth.

\section{Potential Confounders}

Maternal and paternal psychiatric history, parental age at birth, and socioeconomic status predict elevated risk of ASD (27-30). Parental psychiatric history was ascertained from the Stockholm County Council Adult Mental Health Service Register (all adult psychiatric outpatient care in Stockholm County since 1997) $(27,31)$ and the National Patient Register (discharge diagnoses for inpatient psychiatric episodes since 1973) (23). Parental psychiatric history included any psychiatric care in neither, one, or both parents. We recently detailed the relationships between psychotic diagnoses in parents and ASD risk in their offspring in three cohorts (27). The Swedish MultiGeneration Register was used to identify biological first-degree relatives and parental age at birth and parental countries of origin (coded as Sweden or other). The Longitudinal Register for Labor Market Research and Insurance (23) provided prospectively recorded information on socioeconomic status, including income, occupational class, and parental level of educational. Individual disposable family income for biological mothers was coded into quintiles in relation to year of birth. Parental education has been found not to be associated with ASD risk and therefore it was not assessed as a covariate (30). We retrieved data from the Swedish Medical Birth Register (26) on gestational diabetes and hypertension and on congenital malformations in the child, which are known to be associated with abnormal fetal growth (32-34).

\section{Statistical Analysis}

In the nested case-control sample, we conducted conditional logistic regression to calculate crude and adjusted odds ratios with $95 \%$ confidence intervals as estimates of relative risk of ASD overall and ASD with and without intellectual disability in relation to perinatal characteristics. These were adjusted for parental age, country of birth, occupational class, household income, family psychiatric history, gestational diabetes and hypertension, and congenital malformations in the child. Although z scores take gestational age into account, this variable remains a potential confounder of the association of ASD with fetal growth because reduced fetal growth increases the risk of spontaneous preterm birth, and because risk factors for impaired fetal growth and preterm birth overlap $(4,11,12)$. To account for this, and to assess the independence of the observed associations, we examined risk of ASD according to a cross-classification of fetal growth and gestational age. We performed statistical tests of the interaction between gestational age and fetal growth $\mathrm{z}$ scores using the synergy index (35). Analyses were conducted using SPSS, version 20 (IBM, Armonk, N.Y.).
TABLE 1. Characteristics of Children With Autism Spectrum Disorder and Healthy Comparison Subjects in the Stockholm Youth Cohort

\begin{tabular}{|c|c|c|c|c|c|}
\hline \multirow[b]{2}{*}{ Characteristic } & \multicolumn{2}{|c|}{$\begin{array}{c}\text { Case } \\
\text { Subjects } \\
(\mathrm{N}=4,283)\end{array}$} & \multicolumn{2}{|c|}{$\begin{array}{l}\text { Comparison } \\
\text { Subjects } \\
(N=36,588)\end{array}$} & \multirow{2}{*}{$\frac{\text { Analysi }}{p}$} \\
\hline & $\mathrm{N}$ & $\%$ & $\mathrm{~N}$ & $\%$ & \\
\hline Birth weight (g) & & & & & $<0.001$ \\
\hline $500-2,499$ & 239 & 5.6 & 1,154 & 3.2 & \\
\hline $2,500-4,499$ & 3,859 & 90.1 & 34,111 & 93.2 & \\
\hline$>4,500$ & 185 & 4.3 & 1,323 & 3.6 & \\
\hline $\begin{array}{l}\text { Gestational age at } \\
\text { birth (weeks) }\end{array}$ & & & & & $<0.001$ \\
\hline$<33$ & 76 & 1.8 & 291 & 0.8 & \\
\hline $33-36$ & 225 & 5.3 & 1,486 & 4.1 & \\
\hline $37-41$ & 3,584 & 83.7 & 31,729 & 86.7 & \\
\hline$>42$ & 398 & 9.3 & 3,082 & 8.4 & \\
\hline \multicolumn{6}{|l|}{$\begin{array}{l}\text { Parental psychiatric } \\
\text { history }\end{array}$} \\
\hline Mother admitted & 536 & 12.5 & 2,521 & 6.9 & $<0.001$ \\
\hline Father admitted & 479 & 11.2 & 2,494 & 6.8 & $<0.001$ \\
\hline $\begin{array}{l}\text { Lowest two quintiles } \\
\text { for household } \\
\text { income }\end{array}$ & 1,746 & 40.8 & 13,173 & 36.2 & $<0.001$ \\
\hline $\begin{array}{l}\text { Occupation as unskilled } \\
\text { manual worker }\end{array}$ & 755 & 17.6 & 5,033 & 13.8 & $<0.001$ \\
\hline $\begin{array}{l}\text { Mother's country of } \\
\text { birth }\end{array}$ & & & & & $<0.442$ \\
\hline Sweden & 3,308 & 77.2 & 28,448 & 77.8 & \\
\hline Other & 975 & 22.8 & 8,104 & 22.2 & \\
\hline $\begin{array}{l}\text { Maternal gestational } \\
\text { diabetes }\end{array}$ & 21 & 0.5 & 137 & 0.4 & 0.25 \\
\hline $\begin{array}{l}\text { Maternal gestational } \\
\text { hypertension }\end{array}$ & 12 & 0.3 & 110 & 0.3 & 0.82 \\
\hline \multirow{2}{*}{$\begin{array}{l}\text { Congenital } \\
\text { malformation }\end{array}$} & 218 & 5.1 & 1,054 & 2.9 & $<0.001$ \\
\hline & Mean & & Mean & & $\mathrm{p}$ \\
\hline \multicolumn{6}{|l|}{$\begin{array}{l}\text { Parental age at } \\
\text { delivery (years) }\end{array}$} \\
\hline Mother & 29.6 & & 29.4 & & 0.02 \\
\hline Father & 32.7 & & 32.3 & & $<0.001$ \\
\hline
\end{tabular}

\section{Results}

Table 1 summarizes the demographic characteristics of the 4,283 children with ASD and the 36,588 matched comparison subjects (data separating ASD with and without intellectual disabilities are available in the online data supplement).

In large samples, small absolute differences can be statistically significant. In these data, the following differences were of large magnitude and significant: parents of children with ASD were more likely to have experienced psychiatric admission than comparison subjects $(18.7 \%$ and $11.3 \%$, respectively), and children with ASD were more likely than comparison subjects to have congenital malformation. There were small significant differences between children with ASD and comparison subjects on lower occupational class and lower income (see 22, 30). Conditional logistic regression models (Table 2 and Figure 1) 
TABLE 2. Relative Risk of Autism Spectrum Disorder (ASD) by Fetal Growth z Score

\begin{tabular}{|c|c|c|c|c|c|c|c|c|}
\hline \multirow[b]{2}{*}{ Fetal Growth z Score } & \multicolumn{2}{|c|}{$\begin{array}{l}\text { Case Subjects } \\
(\mathrm{N}=4,283)\end{array}$} & \multicolumn{2}{|c|}{$\begin{array}{l}\text { Comparison Subjects } \\
\qquad(\mathrm{N}=36,588)\end{array}$} & \multicolumn{2}{|c|}{ Univariate Analysis } & \multicolumn{2}{|c|}{ Multivariate Analysis } \\
\hline & $\mathrm{N}$ & $\%$ & $\mathrm{~N}$ & $\%$ & Odds Ratio & $95 \% \mathrm{Cl}$ & Adjusted Odds Ratio ${ }^{a}$ & $95 \% \mathrm{Cl}$ \\
\hline$<-2.00$ & 195 & 4.6 & 955 & 2.7 & 1.84 & $1.56-2.16$ & 1.70 & $1.44-2.01$ \\
\hline-1.51 to -2.00 & 230 & 5.4 & 1,654 & 4.5 & 1.24 & $1.07-1.44$ & 1.21 & $1.04-1.41$ \\
\hline-1.01 to -1.50 & 441 & 10.3 & 3,573 & 9.7 & 1.11 & $0.99-1.24$ & 1.08 & $0.97-1.22$ \\
\hline-0.51 to -1.00 & 677 & 15.8 & 5,930 & 16.2 & 1.02 & $0.92-1.12$ & 1.01 & $0.92-1.11$ \\
\hline-0.50 to 0.50 (ref.) & 1,593 & 37.2 & 14,210 & 38.9 & 1.00 & & 1.00 & \\
\hline 0.51 to 1.00 & 504 & 11.8 & 4,888 & 13.3 & 0.92 & $0.83-1.02$ & 0.91 & $0.82-1.02$ \\
\hline 1.01 to 1.50 & 308 & 7.2 & 2,951 & 8.1 & 0.93 & $0.82-1.06$ & 0.91 & $0.80-1.04$ \\
\hline 1.51 to 2.00 & 151 & 3.5 & 1,379 & 3.8 & 0.98 & $0.82-1.17$ & 0.97 & $0.81-1.16$ \\
\hline$>2.00$ & 184 & 4.3 & 1,048 & 2.9 & 1.57 & $1.33-1.85$ & 1.49 & $1.26-1.76$ \\
\hline
\end{tabular}

${ }^{a}$ Adjusted for maternal age, paternal age, parental psychiatric admission, family income at birth, occupational status at birth, mother's country of birth (region), maternal gestational diabetes, maternal gestational hypertension, and congenital malformation in the child.

FIGURE 1. Relative Risk of Autism Spectrum Disorder by Fetal Growth z Score ${ }^{a}$

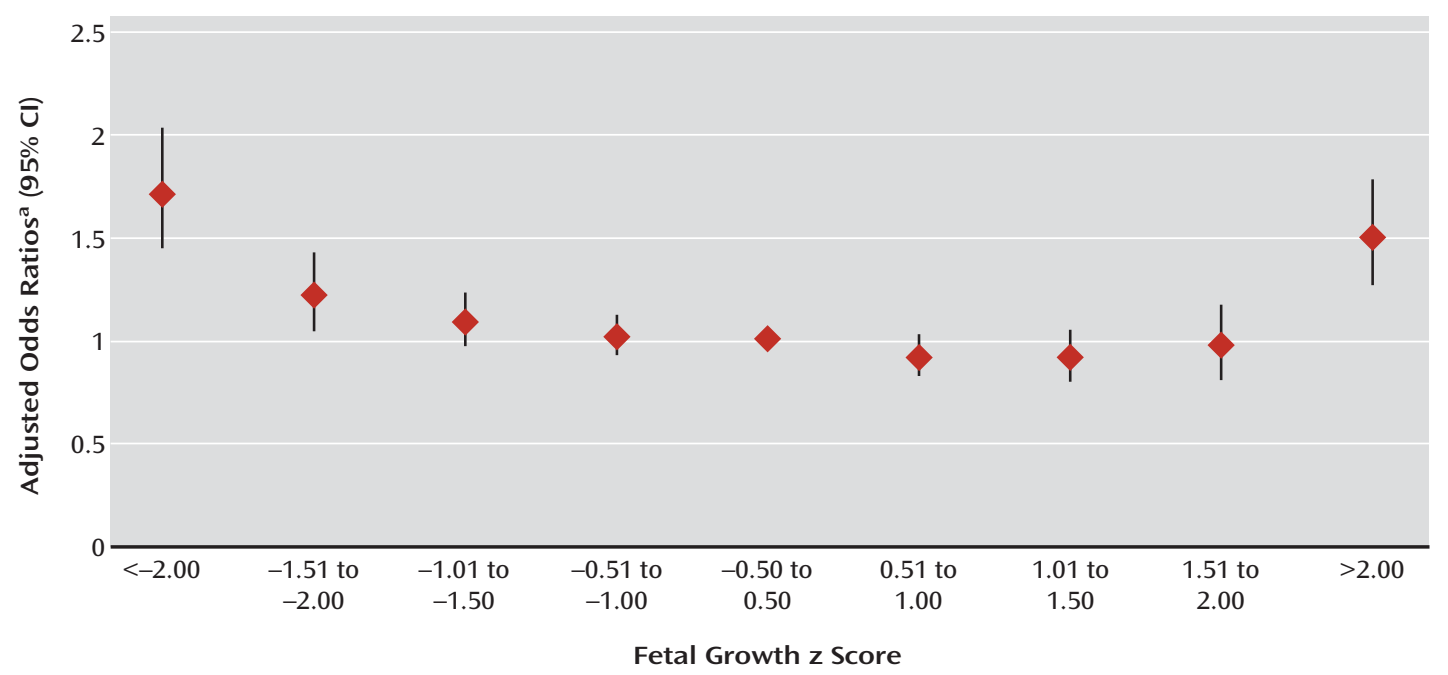

a Adjusted for maternal age, paternal age, parental psychiatric admission, family income at birth, occupational status at birth, mother's country of birth, maternal gestational diabetes, maternal gestational hypertension, and congenital malformation in the child. Children with autism spectrum disorder and healthy comparison subjects were matched for age and sex.

indicated greater ASD risk with fetal growth $\mathrm{z}$ scores 1.50 standard deviations below and $>2.00$ standard deviations above the mean for gestational age. Relative risk rose with increasing deviation below the mean; it was greatest for $<2.00$ standard deviations below the mean (odds ratio $=1.8$, $95 \% \mathrm{CI}=1.6-2.2)$. Above the mean, ASD risk increased only at the extreme $(>2.00$ standard deviations above the mean: odds ratio $=1.6,95 \% \mathrm{CI}=1.3-1.8)$. These relationships followed similar patterns when children with ASD were stratified by sex (see tables in the online data supplement); the interaction between sex and fetal growth was not significant. These relationships were observed for children with ASD with and without comorbid intellectual disability (Table 3). Fetal growth below the mean was more strongly associated with ASD with intellectual disability than without $(\mathrm{p}<0.004)$. Parental age, psychiatric history, socioeconomic status, country of birth, congenital malformation in the child, and gestational diabetes and hypertension had only modest confounding effects on the relationship between fetal growth and ASD with and without intellectual disability (Tables 2 and 3).

Table 4 summarizes the relationships between fetal growth, gestational age, and ASD risk. Children born small or large for gestational age were at greater ASD risk across all gestational age strata. Regardless of fetal growth, prematurity was positively associated with elevated risk. We observed an interaction between fetal growth and gestational age, such that growth restriction conferred particularly greater risk in children born postterm (synergy index 3.0, 95\% CI=1.3-6.6). Patterns of risk were similar for ASD with intellectual disability and ASD without intellectual disability, but we observed stronger effects in the ASD with intellectual disability group (data available on request).

\section{Discussion}

To our knowledge, this is the first large prospective population-based study to describe the association between 
TABLE 3. Relative Risk of Autism Spectrum Disorder (ASD) With and Without Intellectual Disability

\begin{tabular}{|c|c|c|c|c|c|c|c|c|}
\hline \multirow{2}{*}{$\begin{array}{l}\text { Classification and Fetal } \\
\text { Growth z Score }\end{array}$} & \multicolumn{2}{|c|}{ Case Subjects } & \multicolumn{2}{|c|}{ Comparison Subjects } & \multicolumn{2}{|c|}{ Univariate Analysis } & \multicolumn{2}{|c|}{ Multivariate Analysis } \\
\hline & $\mathrm{N}$ & $\%$ & $\mathrm{~N}$ & $\%$ & Odds Ratio & $95 \% \mathrm{Cl}$ & Adjusted Odds Ratio ${ }^{a}$ & $95 \% \mathrm{Cl}$ \\
\hline $\begin{array}{l}\text { ASD with intellectual } \\
\text { disability }\end{array}$ & 1,755 & & 14,979 & & & & & \\
\hline$<-2.00$ & 100 & 5.7 & 371 & 2.5 & 2.51 & $1.98-3.18$ & 2.22 & $1.74-2.83$ \\
\hline-1.51 to -2.00 & 99 & 5.6 & 641 & 4.3 & 1.44 & $1.14-1.81$ & 1.33 & $1.05-1.67$ \\
\hline-1.01 to -1.50 & 203 & 11.6 & 1,453 & 9.7 & 1.30 & $1.10-1.54$ & 1.25 & $1.05-1.48$ \\
\hline-0.51 to -1.00 & 288 & 16.4 & 2,453 & 16.4 & 1.09 & $0.94-1.26$ & 1.06 & $0.91-1.23$ \\
\hline-0.50 to 0.50 (ref.) & 619 & 35.3 & 5,748 & 38.4 & 1.00 & & 1.00 & \\
\hline 0.51 to 1.00 & 191 & 10.9 & 2,076 & 13.9 & 0.85 & $0.72-1.01$ & 0.87 & $0.73-1.03$ \\
\hline 1.01 to 1.50 & 120 & 6.8 & 1,222 & 8.2 & 0.91 & $0.74-1.12$ & 0.91 & $0.74-1.12$ \\
\hline 1.51 to 2.00 & 54 & 3.1 & 580 & 3.9 & 0.87 & $0.65-1.16$ & 0.86 & $0.64-1.16$ \\
\hline$>2.00$ & 81 & 4.6 & 435 & 2.9 & 1.72 & $1.34-2.22$ & 1.63 & $1.26-2.11$ \\
\hline $\begin{array}{l}\text { ASD without intellectual } \\
\text { disability }\end{array}$ & 2,528 & & 21,609 & & & & & \\
\hline$<-2.00$ & 95 & 3.8 & 584 & 2.7 & 1.43 & $1.14-1.79$ & 1.35 & $1.07-1.71$ \\
\hline-1.51 to -2.00 & 131 & 5.2 & 1,013 & 4.7 & 1.12 & $0.93-1.36$ & 1.12 & $0.92-1.36$ \\
\hline-1.01 to -1.50 & 238 & 9.4 & 2,120 & 9.8 & 0.98 & $0.84-1.14$ & 0.97 & $0.84-1.13$ \\
\hline-0.51 to -1.00 & 389 & 15.4 & 3,477 & 16.1 & 0.97 & $0.86-1.10$ & 0.98 & $0.86-1.11$ \\
\hline-0.50 to 0.50 (ref.) & 974 & 38.5 & 8,462 & 39.1 & 1.00 & & 1.00 & \\
\hline 0.51 to 1.00 & 313 & 12.4 & 2,812 & 13.0 & 0.97 & $0.84-1.11$ & 0.95 & $0.83-1.09$ \\
\hline 1.01 to 1.50 & 188 & 7.4 & 1,729 & 8.0 & 0.94 & $0.80-1.11$ & 0.91 & $0.77-1.07$ \\
\hline 1.51 to 2.00 & 97 & 3.8 & 799 & 3.7 & 1.06 & $0.85-1.32$ & 1.02 & $0.82-1.28$ \\
\hline$>2.00$ & 103 & 4.1 & 613 & 2.8 & 1.47 & $1.18-1.82$ & 1.38 & $1.10-1.72$ \\
\hline
\end{tabular}

a Adjusted for maternal age, paternal age, parental psychiatric admission, family income at birth, occupational status at birth, mother's country of birth, maternal gestational diabetes, maternal gestational hypertension, and congenital malformation in the child.

deviance in fetal growth and ASD in children with and without comorbid intellectual disability. There were four main findings. First, poor fetal growth was related to greater risk of ASD, which was most evident at the extreme of poor fetal growth (i.e., $<2.00$ standard deviations below the mean). Second, deviance in growth at the opposite distribution extreme $(>2.00$ standard deviations above the mean) was also related to increased risk. Third, although patterns were similar overall for ASD with and without intellectual disability, the association with poor fetal growth was stronger for ASD with intellectual disability. Fourth, preterm birth was associated with greater ASD risk independently of poor fetal growth, and vice versa.

Although the results of some population studies were inconclusive $(16,18,19)$, our findings are broadly consistent with previous studies that used birth weight as a proxy for fetal growth and reported significant associations between increased ASD risk and low birth weight (i.e., $<2.5 \mathrm{~kg}$ as defined by the World Health Organization) $(14,15,17)$. A recent study of a low birth weight cohort (36) also reported a significant positive association between ASD and birth weight below $2 \mathrm{~kg}$, and a contemporary meta-analysis reported a significant association with low birth weight (relative risk $=1.63,95 \% \mathrm{CI}=1.19-2.33$ ) and with small-for-gestational-age infants (relative risk $=1.35$, 95\% CI=1.14-1.61) (37). To our knowledge, the association between ASD and fetal growth 2.00 standard deviations above the mean has not been previously reported. This association reached significance in all models and was robust in children with ASD with and without intellectual disability. Smaller population studies (16-18, 20, 38, 39) and meta-analyses (37) reported either no risk or nonsignificant excess risk above 4.5 or $5 \mathrm{~kg}$ or in large-for-gestational-age infants, which likely reflects insufficient statistical power in these studies to examine this association.

Prematurity was also associated with an elevated ASD risk. The independent effects of fetal growth and gestational age were consistent with those reported in previous studies $(16,17,20,38)$. We also report significant interaction such that postmature, small-for-gestational-age infants showed particularly elevated ASD risks (18). These infants may be dysmature, but postmaturity may also indicate abnormality of the fetal-placental unit, including placental insensitivity to processes that initiate delivery. In this case, infants exposed longest to factors associated with growth restriction, such as poor placental function, may be at greatest risk for poor outcome. Future research could usefully explore whether measures of fetal growth or gestational age are proxy exposures for such fetoplacental dysfunction.

Most previous studies did not distinguish case subjects with or without intellectual disability. Eaton et al. (18) reported increased risk only of ASD without intellectual disability in children with low birth weight, but not in small-for-gestational-age children, although the number of cases was small and the authors did not report associations for large for gestational age or high birth weight. Leonard et al. (39) studied children with ASD within an 
TABLE 4. Relative Risk of Autism Spectrum Disorder (ASD) With Intellectual Disability

\begin{tabular}{|c|c|c|c|c|c|c|c|c|}
\hline \multirow[b]{2}{*}{$\begin{array}{l}\text { Gestational Age and } \\
\text { Fetal Growth z Score }\end{array}$} & \multicolumn{2}{|c|}{ Case Subjects $(\mathrm{N}=4,283)$} & \multicolumn{2}{|c|}{$\begin{array}{l}\text { Comparison Subjects } \\
\qquad(\mathrm{N}=36,588)\end{array}$} & \multicolumn{2}{|c|}{ Univariate Analysis } & \multicolumn{2}{|c|}{ Multivariate Analysis } \\
\hline & $\mathrm{N}$ & $\%$ & $\mathrm{~N}$ & $\%$ & Odds Ratio & $95 \% \mathrm{Cl}$ & $\begin{array}{l}\text { Adjusted } \\
\text { Odds Ratio }^{\mathrm{a}}\end{array}$ & $95 \% \mathrm{Cl}$ \\
\hline \multicolumn{9}{|l|}{$<33$ weeks } \\
\hline$<-2.00$ & 21 & 0.5 & 57 & 0.2 & 3.47 & $2.10-5.75$ & 3.28 & $1.97-5.47$ \\
\hline-0.51 to -2.00 & 27 & 0.6 & 114 & 0.3 & 2.13 & $1.39-3.25$ & 1.89 & $1.23-2.91$ \\
\hline-0.50 to 0.50 & 17 & 0.4 & 73 & 0.2 & 2.14 & $1.26-3.65$ & 2.05 & $1.19-3.51$ \\
\hline 0.51 to 2.00 & 10 & 0.2 & 38 & 0.1 & 2.40 & $1.19-4.82$ & 2.34 & $1.15-4.76$ \\
\hline$>2.00$ & 1 & 0.0 & 9 & 0.0 & 1.04 & $0.13-8.20$ & 1.04 & $0.11-7.34$ \\
\hline \multicolumn{9}{|l|}{ 33-36 weeks } \\
\hline$<-2.00$ & 26 & 0.6 & 117 & 0.3 & 2.02 & $1.31-3.10$ & 1.90 & $1.23-2.93$ \\
\hline-0.51 to -2.00 & 76 & 1.8 & 435 & 1.2 & 1.60 & $1.24-2.05$ & 1.54 & $1.20-1.99$ \\
\hline-0.50 to 0.50 & 70 & 1.6 & 506 & 1.4 & 1.27 & $0.98-1.64$ & 1.18 & $0.91-1.54$ \\
\hline 0.51 to 2.00 & 42 & 1.0 & 351 & 1.0 & 1.11 & $0.80-1.54$ & 1.05 & $0.76-1.46$ \\
\hline$>2.00$ & 11 & 0.3 & 77 & 0.2 & 1.30 & $0.69-2.45$ & 1.15 & $0.60-2.18$ \\
\hline \multicolumn{9}{|l|}{ 37-41 weeks } \\
\hline$<-2.00$ & 119 & 2.8 & 692 & 1.9 & 1.60 & $1.30-1.95$ & 1.46 & $1.19-1.80$ \\
\hline-0.51 to -2.00 & 1,097 & 25.6 & 9,454 & 25.8 & 1.06 & $0.98-1.16$ & 1.05 & $0.97-1.15$ \\
\hline-0.50 to 0.50 (ref.) & 1,356 & 31.7 & 12,420 & 33.9 & 1.00 & & 1.00 & \\
\hline 0.51 to 2.00 & 848 & 19.8 & 8,239 & 22.5 & 0.94 & $0.86-1.03$ & 0.93 & $0.85-1.02$ \\
\hline$>2.00$ & 164 & 3.8 & 924 & 2.5 & 1.62 & $1.36-1.94$ & 1.55 & $1.29-1.85$ \\
\hline \multicolumn{9}{|l|}{$>42$ weeks } \\
\hline$<-2.00$ & 29 & 0.7 & 89 & 0.2 & 2.95 & $1.93-4.51$ & 2.72 & $1.76-4.18$ \\
\hline-0.51 to -2.00 & 148 & 3.5 & 1,154 & 3.2 & 1.17 & $0.97-1.40$ & 1.13 & $0.94-1.36$ \\
\hline-0.50 to 0.50 & 150 & 3.5 & 1,211 & 3.3 & 1.12 & $0.94-1.35$ & 1.12 & $0.93-1.34$ \\
\hline 0.51 to 2.00 & 63 & 1.5 & 590 & 1.6 & 0.98 & $0.75-1.27$ & 0.97 & $0.74-1.26$ \\
\hline$>2.00$ & 8 & 0.2 & 38 & 0.1 & 1.95 & $0.91-4.19$ & 2.02 & $0.94-4.38$ \\
\hline
\end{tabular}

${ }^{a}$ Adjusted for maternal age, paternal age, parental psychiatric admission, family income at birth, occupational status at birth, mother's country of birth, maternal gestational diabetes, maternal gestational hypertension, and congenital malformation in the child.

intellectual disability cohort in Western Australia. In a relatively small number of children with comorbid intellectual disability and ASD, they reported no associations between birth weight or gestational age and the odds of ASD with intellectual disability. Infants born $24 \%$ above optimal birth weight were more likely to be diagnosed with ASD with intellectual disability, but the wide confidence interval (odds ratio $=2.36,95 \% \mathrm{CI}=0.93-6.03$ ) indicates limited statistical power. Our findings suggest that the degree to which an infant deviates from its optimal growth, at the extremes of higher or lower deviation from the mean, increases the risk of ASD with or without intellectual disability.

\section{Strengths and Limitations}

This study is distinguished by particularly strong features. It was truly a population-based study rather than an inpatient or hospital discharge sample. The study sample contained nearly complete prenatal and outcome data with a very large sample size, and we were able to adjust for a comprehensive range of relevant confounders.

There are some important limitations to consider. Apart from gestational diabetes and hypertension, we did not adjust for intranatal or postneonatal events or maternal and neonatal morbidity. Swedish data suggest that maternal and neonatal morbidity are likely to be risk mediators (24), and therefore inclusion may bias estimates. We did not measure a number of maternal factors that may be involved in poor fetal growth (e.g., alcohol and substance misuse, exposure to prescribed medication, or nutritional influences) (40). Similarly, maternal prepregnancy obesity and gestational weight gain may also be involved in the development of macrosomia (birth weight $>4 \mathrm{~kg}$ or $>90$ th percentile) (41). A measure of head circumference at birth was available, but we were unable to adjust for this because it was not measured consistently across the study period. We adjusted for psychiatric illness in mothers and fathers, but cannot account for a range of family-level effects that may be confounders (42). Dodds et al. (20) suggested that children with a positive family history of mental illness, including autism, may be predisposed both to suboptimal obstetric factors and to ASD. Nonetheless, a recent large population study (43) using a cotwin-control design reported that in twin pairs discordant for birth weight, twins with lower birth weight were significantly more likely to score above the cutoff for likely clinical disorder on a scale predictive of ASD. This twin-control design reduces potential confounding that might influence the association between birth weight and ASD, and the results imply that nongenetic influences associated with birth weight may indeed be important antecedents in the development of ASD (42). Finally, it 
would have been interesting to compare our findings with a well-defined control group of children who had intellectual disability but not ASD, but this was not available in the present study.

Deviance in fetal somatic growth may co-occur with abnormalities in the trajectory of fetal brain development in ways that are specifically, or nonspecifically, linked to ASD. Like the association between fetal growth restriction and lower IQ in the general population $(9,42,44)$, fetal growth restriction may favor the development of ASD with intellectual disability and could provide clues to the mechanisms specific to this aspect of illness. There remains a need to investigate how and why fetal growth that deviates from the population average is related to greater risk of ASD in children.

Research into the control of fetal somatic and brain growth increasingly implicates placental function and early placental programming of infant development (4). In adult metabolic and cardiovascular risk, examination of the ways in which environmental and genetic influences on development interact has shown that environmental perturbations during fetal development have a lifelong effect on the gene-informed trajectory of endocrine and cardiovascular homeostatic systems $(4,11,45)$. Studies such as these are paving the way for novel preventive approaches to disease risk (46).

Macrosomia was associated to a similar degree with higher risk of ASD with and without intellectual disability, and elevated risks persisted after adjusting for gestational diabetes. Genetic and epigenetic influences on macrosomia may have some specific effects on aspects of ASD pathophysiology that are not associated with intellectual functioning. Macrosomia and its important risk factorsgestational obesity and diabetes-are increasingly prevalent. Similarly, possible risk factors for reduced fetal growth, including maternal smoking, alcohol, and medication use, may be especially important given the greater likelihood that parents of children with ASD have a mental illness (27). Further research is required to determine whether deviant fetal growth is a predictor or a cause of ASD, although these risk factors present an attractive target for primary prevention of idiopathic ASD because they are easy to identify and amenable to intervention (e.g., by preventing maternal obesity). Prematurity also increased the risk of ASD independently of fetal growth. Thus, although the majority of children with ASD were term infants, the improved survival of preterm infants suggests that this remains an important target for preventive intervention.

Overall, we believe that these findings provide important information for clinicians and parents. Associations of ASD risk with deviance in fetal growth suggest the possibility of early intervention to reduce poor developmental outcomes through careful antenatal monitoring as well as follow-up, screening, and management of infants who may be most at risk.

\section{Conclusions}

Deviance in fetal growth below the mean, particularly at its extremes, and preterm birth are strong independent risk factors for later ASD, especially with comorbid intellectual disability. By contrast, fetal growth at the extreme above the mean is linked with increased risk of ASD regardless of intellectual disability. These robust associations between ASD, fetal growth, and preterm birth provide further impetus for research assessing genetic as well as environmental risk in ASD. Understanding how genetic and environmental factors might influence fetal growth and its control during critical developmental periods may reveal important insights into the etiology of ASD.

Received April 24, 2012; revisions received Sept. 27 and Oct. 25, 2012; accepted Oct. 30, 2012 (doi: 10.1176/appi.ajp.2012. 12040543). From the Center for Women's Mental Health and the Center for Mental Health and Risk, Manchester Academic Health Sciences Center, University of Manchester, U.K.; the Division of Public Health Epidemiology, Department of Public Health Sciences, Karolinska Institute, Norrbacka, Karolinska University Hospital, Stockholm; the Academic Unit of Psychiatry, School of Social and Community Medicine, University of Bristol, U.K.; the Avon and Wiltshire Partnership NHS Mental Health Trust, Bristol; and the Imprints Center for Genetic and Environmental Life Course Studies, Mailman School of Public Health and New York State Psychiatric Institute, Columbia University, New York. Address correspondence to Dr. Abel (kathryn.abel@manchester.ac.uk).

The authors report no financial relationships with commercial interests.

\section{References}

1. Centers for Disease Control and Prevention: Prevalence of autism spectrum disorders: autism and developmental disabilities monitoring network: 14 sites, United States, 2008. Morbidity and Mortality Weekly Report 2012; 61:1-19 (http://www.cdc. gov/mmwr/PDF/ss/ss6103.pdf)

2. Hallmayer J, Cleveland S, Torres A, Phillips J, Cohen B, Torigoe T, Miller J, Fedele A, Collins J, Smith K, Lotspeich L, Croen LA, Ozonoff S, Lajonchere C, Grether JK, Risch N: Genetic heritability and shared environmental factors among twin pairs with autism. Arch Gen Psychiatry 2011; 68:1095-1102

3. State M, Levitt P: The conundrums of understanding genetic risks for autism spectrum disorders. Nat Neurosci 2011; 14:1499-1506

4. Abel KM, Allin MA: Placental programming and neurodevelopmental outcomes, in Placenta and Neurodisability. Edited by Baker P, Sibley C. London, The MacKeith Press, 2005

5. Abel KM, Wicks S, Susser ES, Dalman C, Pedersen MG, Mortensen PB, Webb RT: Birth weight, schizophrenia, and adult mental disorder: is risk confined to the smallest babies? Arch Gen Psychiatry 2010; 67:923-930

6. Veen S, Ens-Dokkum MH, Schreuder AM, Verloove-Vanhorick SP, Brand R, Ruys JH: Impairments, disabilities, and handicaps of very preterm and very-low-birthweight infants at five years of age: The Collaborative Project on Preterm and Small for Gestational Age Infants (POPS) in The Netherlands. Lancet 1991; 338:33-36

7. Pharoah PO, Stevenson CJ, Cooke RW, Stevenson RC: Prevalence of behaviour disorders in low birthweight infants. Arch Dis Child 1994; 70:271-274

8. Johnson EO, Breslau N: Increased risk of learning disabilities in low birth weight boys at age 11 years. Biol Psychiatry 2000; 47: 490-500 
9. Eriksen W, Sundet JM, Tambs K: Birth weight standardized to gestational age and intelligence in young adulthood: a registerbased birth cohort study of male siblings. Am J Epidemiol 2010; 172:530-536

10. Charman T, Pickles A, Simonoff E, Chandler S, Loucas T, Baird G: IQ in children with autism spectrum disorders: data from the Special Needs and Autism Project (SNAP). Psychol Med 2011; 41: 619-627

11. Leon DA, Lithell HO, Vâgerö D, Koupilová I, Mohsen R, Berglund L, Lithell UB, McKeigue PM: Reduced fetal growth rate and increased risk of death from ischaemic heart disease: cohort study of 15,000 Swedish men and women born 1915-29. BM] 1998; 317:241-245

12. Hutcheon JA, Platt RW: The missing data problem in birth weight percentiles and thresholds for "small-for-gestational-age." Am J Epidemiol 2008; 167:786-792

13. Høgberg U, Larsson N: Early dating by ultrasound and perinatal outcome: a cohort study. Acta Obstet Gynecol Scand 1997; 76 : 907-912

14. Gillberg C, Gillberg IC: Infantile autism: a total population study of reduced optimality in the pre-, peri-, and neonatal period. J Autism Dev Disord 1983; 13:153-166

15. Mason-Brothers A, Ritvo ER, Pingree C, Petersen PB, Jenson WR, McMahon WM, Freeman BJ, Jorde LB, Spencer MJ, Mo A, Ritvo A: The UCLA-University of Utah epidemiologic survey of autism: prenatal, perinatal, and postnatal factors. Pediatrics 1990; 86:514-519

16. Hultman CM, Sparén P, Cnattingius S: Perinatal risk factors for infantile autism. Epidemiology 2002; 13:417-423

17. Larsson HJ, Eaton WW, Madsen KM, Vestergaard M, Olesen AV, Agerbo E, Schendel D, Thorsen P, Mortensen PB: Risk factors for autism: perinatal factors, parental psychiatric history, and socioeconomic status. Am J Epidemiol 2005; 161:916-925, discussion 926-928

18. Eaton WW, Mortensen PB, Thomsen PH, Frydenberg M: Obstetric complications and risk for severe psychopathology in childhood. J Autism Dev Disord 2001; 31:279-285

19. Glasson EJ, Bower C, Petterson B, de Klerk N, Chaney G, Hallmayer JF: Perinatal factors and the development of autism: a population study. Arch Gen Psychiatry 2004; 61:618-627

20. Dodds L, Fell DB, Shea S, Armson BA, Allen AC, Bryson S: The role of prenatal, obstetric and neonatal factors in the development of autism. J Autism Dev Disord 2011; 41:891-902

21. Magnusson C, Rai D, Goodman A, Lundberg M, Idring S, Svensson A, Koupil I, Serlachius E, Dalman C: Migration and autismspectrum disorder: population-based study. $\mathrm{Br} J$ Psychiatry 2012; 201:109-115

22. Idring S, Rai D, Dal H, Dalman C, Sturm H, Zander E, Lee B, Serlachius E, Magnusson C: Autism spectrum disorders in the Stockholm Youth Cohort: design, prevalence and validity. PLoS One 2012; 7:e41280

23. Statistics Sweden: Longitudinal Integration Database for Health Insurance and Labor Market Studies. http://www.scb.se/Pages/ List_257743.aspx

24. Child Health Care Stockholm County Council: Primary Child Health Care. http://www.webbhotell.sll.se/bhv/

25. Lord C, Petkova E, Hus V, Gan W, Lu F, Martin DM, Ousley O, Guy L, Bernier R, Gerdts J, Algermissen M, Whitaker A, Sutcliffe JS, Warren Z, Klin A, Saulnier C, Hanson E, Hundley R, Piggot J, Fombonne E, Steiman M, Miles J, Kanne SM, Goin-Kochel RP, Peters SU, Cook EH, Guter S, Tjernagel J, Green-Snyder L-A, Bishop S, Esler A, Gotham K, Luyster R, Miller F, Olson J, Richler J, Risi S: A multi-site study of the clinical diagnosis of different autism spectrum disorders. Arch Gen Psychiatry 2012; 69:306-313

26. Stockholm: The National Board of Health and Welfare. The Swedish Centre for Epidemiology: The Swedish Medical Birth Register: a summary of content and quality. 2003. http://www. socialstyrelsen.se/publikationer2003/2003-112-3
27. Sullivan PF, Magnusson C, Reichenberg A, Boman M, Dalman C, Davidson $\mathrm{M}$, Fruchter $\mathrm{E}$, Hultman $\mathrm{CM}$, Lundberg $\mathrm{M}$, Långström $\mathrm{N}$, Weiser M, Svensson AC, Lichtenstein P: Family history of schizophrenia and bipolar disorder as risk factors for autism. Arch Gen Psychiatry 2012; 69:1099-1103

28. Hultman CM, Sandin S, Levine SZ, Lichtenstein P, Reichenberg A: Advancing paternal age and risk of autism: new evidence from a population-based study and a meta-analysis of epidemiological studies. Mol Psychiatry 2011; 16:1203-1212

29. Bhasin TKS, Schendel D: Sociodemographic risk factors for autism in a US metropolitan area. J Autism Dev Disord 2007; 37:667-677

30. Rai D, Lewis G, Lundberg M, Araya R, Svensson A, Dalman C, Carpenter P, Magnusson C: Parental socioeconomic status and risk of offspring autism spectrum disorders in a Swedish population-based study. J Am Acad Child Adolesc Psychiatry 2012; 51:467-476

31. Jörgensen L, Ahlbom A, Allebeck P, Dalman C: The Stockholm non-affective psychoses study (SNAPS): the importance of including out-patient data in incidence studies. Acta Psychiatr Scand 2010; 121:389-392

32. Kjos SL, Buchanan TA: Gestational diabetes mellitus. N Engl J Med 1999; 341:1749-1756

33. Xiong X, Mayes D, Demianczuk N, Olson DM, Davidge ST, NewburnCook C, Saunders LD: Impact of pregnancy-induced hypertension on fetal growth. Am J Obstet Gynecol 1999; 180:207-213

34. Kramer MS, Platt RW, Wen SW, Joseph KS, Allen A, Abrahamowicz M, Blondel B, Bréart G; Fetal/Infant Health Study Group of the Canadian Perinatal Surveillance System: A new and improved population-based Canadian reference for birth weight for gestational age. Pediatrics 2001; 108:E35

35. Lundberg M, Fredlund P, Hallqvist J, Diderichsen F: A SAS program calculating three measures of interaction with confidence intervals. Epidemiology 1996; 7:655-656

36. Pinto-Martin JA, Levy SE, Feldman JF, Lorenz JM, Paneth N, Whitaker AH: Prevalence of autism spectrum disorder in adolescents born weighing $<2,000$ grams. Pediatrics 2011; 128:883-891

37. Gardener H, Spiegelman D, Buka SL: Perinatal and neonatal risk factors for autism: a comprehensive meta-analysis. Pediatrics 2011; 128:344-355

38. Buchmayer S, Johansson S, Johansson A, Hultman CM, Sparén P, Cnattingius S: Can association between preterm birth and autism be explained by maternal or neonatal morbidity? Pediatrics 2009; 124:e817-e825

39. Leonard H, Nassar N, Bourke J, Blair E, Mulroy S, de Klerk N, Bower C: Relation between intrauterine growth and subsequent intellectual disability in a ten-year population cohort of children in Western Australia. Am J Epidemiol 2008; 167:103-111

40. Aylward EH, Minshew NJ, Field K, Sparks BF, Singh N: Effects of age on brain volume and head circumference in autism. Neurology 2002; 59:175-183

41. Galtier-Dereure F, Boegner C, Bringer J: besity and pregnancy: complications and cost. Am J Clin Nutr 2000; 71(suppl): 1242S-1248S

42. Susser E, Eide MG, Begg M: Invited commentary: the use of sibship studies to detect familial confounding. Am J Epidemiol 2010; 172:537-539

43. Losh M, Esserman D, Anckarsäter H, Sullivan PF, Lichtenstein P: Lower birth weight indicates higher risk of autistic traits in discordant twin pairs. Psychol Med 2012; 42:1091-1102

44. Richards M, Hardy R, Kuh D, Wadsworth MEJ: Birth weight and cognitive function in the British 1946 birth cohort: longitudinal population based study. BMJ 2001; 322:199-203

45. Smith NH, Ozanne SE: Intrauterine origins of metabolic disease. Reviews in Gynaecological and Perinatal Practice 2006; 6:211-217

46. Jansson T, Powell TL: Role of the placenta in fetal programming: underlying mechanisms and potential interventional approaches. Clin Sci (Lond) 2007; 113:1-13 